\title{
Is Adenoidectomy Preventable?
}

\author{
Giorgio Ciprandi ${ }^{1}$ (1), Ignazio La Mantia ${ }^{2}$ (1), Attilio Varricchio ${ }^{3}$ (1) \\ ${ }^{1}$ Department of Internal Medicine, Ospedale Policlinico San Martino, Genoa, Italy \\ Letter to the Editor $>{ }^{2}$ Department of Otolaryngology, University of Catania, Catania, Italy \\ ${ }^{3}$ Department of Otolaryngology, Ospedale San Gennaro, Naples, Italy
}

\section{Dear Editor,}

Adenoidectomy generates resounding interest and deserves thoughtful consideration. Recently, some papers that mainly concern surgery revision have been published regarding this topic $(1,2)$. Thus, knowing the risk factors associated with surgery decision has profound clinical and social relevance.

Recurrent infections, including recurring otitis media (ROM) and adenoid hypertrophy (AH), are common indications for adenoidectomy (3). Consequently, acting on these factors could reduce the requirement for surgery. A new approach to prevent respiratory infections, including otitis, involves microbiome analysis. Actually, the upper airway microbiome could affect the growth of pathogens residing in the rhinopharynx. In this regard, "bacteriotherapy," such as the administration of "good" bacteria, could prevent the onset of respiratory infections and consequently avoid antibiotic resistance (4). A mixture of Streptococcus salivarius $24 \mathrm{SMB}$ and Streptococcus oralis 89 a (administered as an intranasal spray, Rinogermina, DMG, Rome, Italy) colonizes the intestinal tract (5) and has been effective in children suffering from ROM (6). Therefore, we tested the hypothesis concerning the possibility of preventing surgery treating a group of 44 children (30 males, mean age 4.9 years) suffering from $\mathrm{AH}$ and $\mathrm{OM}$ with effusion (OME) who were waiting for adenoidectomy and tympanocentesis.

The children were randomly (with a ratio $1: 1$ ) treated with bacteriotherapy (Group A) or with hypertonic nasal lavage (Group B). Bacteriotherapy (Streptococcus salivarius 24SMB and Streptococ- cus oralis $89 \mathrm{a}$ ) or nasal lavage were prescribed as 2 puffs for nostril twice/day for 7 days for 4 consecutive months.

The study conformed to the ethical criteria concerning the management of clinical data and was conducted in accordance with the principles of the Declaration of Helsinki; a written informed consent was obtained from each parent of children.

Fiberoptic endoscopy and tympanometry were performed before and after treatment. Adenoid size was measured according to validated criteria with a $0-4$ score (7). Statistical analysis was performed using the chi-square test and ANOVA, with Bonferroni post-hoc tests (SPSS version 20, IBM, USA).

After treatment, only 6 children of Group A required surgery, whereas 20 children of Group B $(\mathrm{p}<0.0001)$ (Figure 1a). The adenoid size was 4 in all children at baseline; after treatment 11 (50\%) children had size 3 (23\%) and 5 had size 2 in Group A, whereas only 2 (9\%) children of Group $B$ had size 3 ( $p<0.0001$, Figure 1b). About tympanometry, all children had type $\mathrm{B}$ at baseline; after treatment 36 (82\%) ears showed type $\mathrm{C}$ and no subjects had bilateral type B in Group A, whereas Group B showed 3 (7\%) type C and 1 (2\%) type A $(\mathrm{p}<0.0001$, Figure 1c).

To avoid adenoidectomy is an issue particularly relevant for both otolaryngologists and paediatricians. There is evidence about potential risk factors involved in this issue (1-3), but studies exploring potential preventive treatments are inconsistent. Re- 


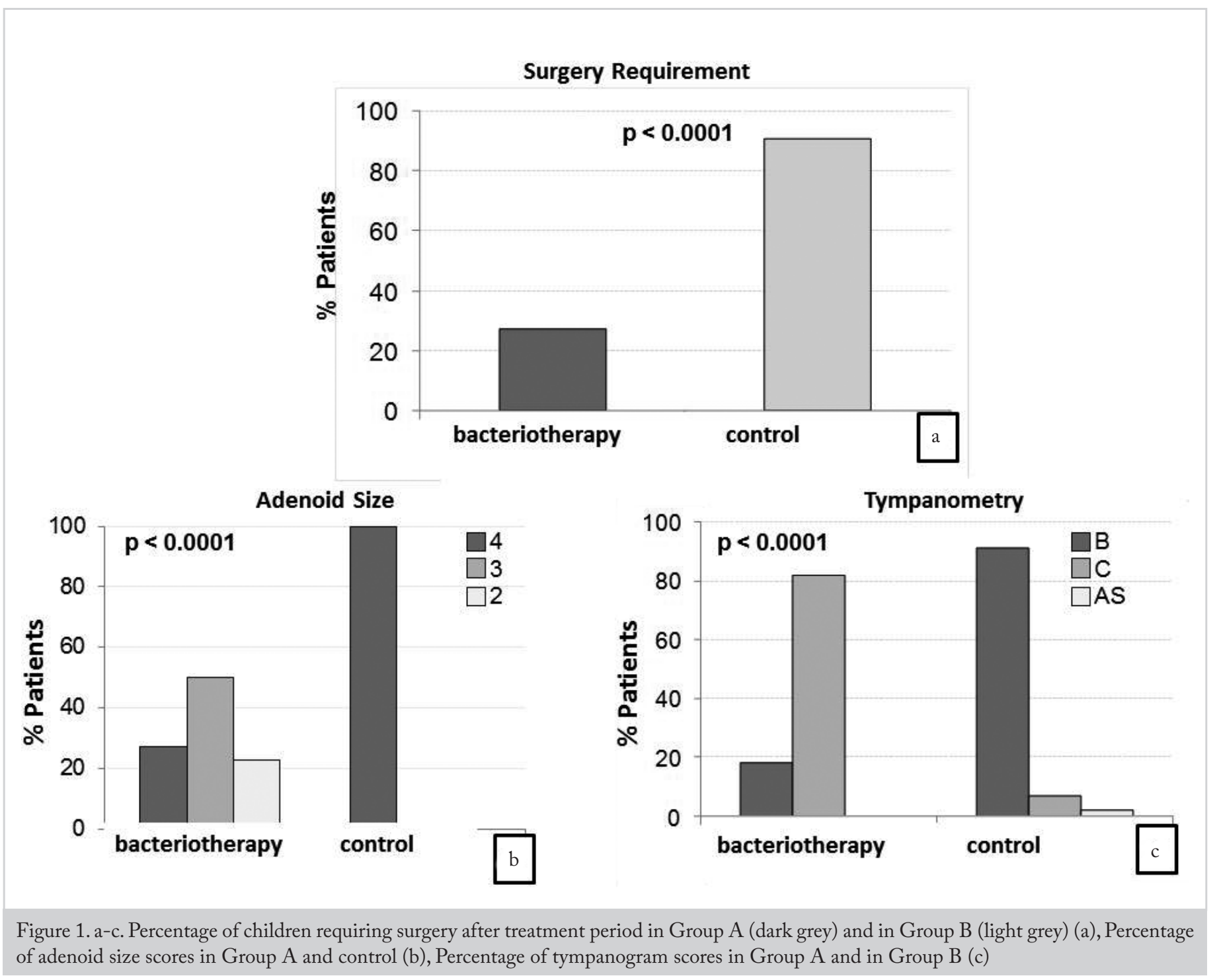

spiratory infections, including OM, may more frequently occur in the presence of some microbiota $(8,9)$. So, "bacteriotherapy" may represent an interesting alternative to current treatments. In fact, some non-pathogenic strains may prevent microbial infections contrasting their rooting into the enteric mucosa.

The present experience reported that Streptococcus salivarius $24 \mathrm{SMB}$ and Streptococcus oralis 89 a nasal spray could reduce the adenoidectomy indication in many actively treated patients. In addition, treated children experienced improved tympanometry results.

This preliminary experience could suggest that Streptococcus salivarius $24 \mathrm{SMB}$ and Streptococcus oralis 89 a nasal spray may be a reliable option in possible surgery prevention. Interestingly, no side effects were reported, and all children tolerated the bacteriotherapy.

However, the limitations of the present study are as follows: (i) open and retrospective study, (ii) without a true placebo group, (iii) without cultural investigations, and (iv) the random allocation was arbitrarily decided by the doctor.
In summary, the present observation could suggest that Streptococcus salivarius $24 \mathrm{SMB}$ and Streptococcus oralis 89 a nasal spray could prevent adenoid surgery.

Peer-review: Externally peer-reviewed.

Author Contributions: Concept - G.C., I.L.M., A.V.; Design - G.C., I.L.M., A.V.; Supervision - G.C., I.L.M., A.V.; Materials - I.L.M., A.V.; Data Collection and/or Processing - I.L.M., A.V.; Analysis and/ or Interpretation - G.C.; Literature Search - G.C.; Writing - G.C.; Critical Reviews - I.L.M., A.V.

Conflict of Interest: The authors have no conflicts of interest to declare

Financial Disclosure: The authors declared that this study has received no financial support.

\section{References}

1. Sunnergren O, Odhagen E, Stalfors J. Incidence of second surgery following pediatric adenotonsillar surgery: a population-based cohort study. Eur Arch Otorhinolaryngol 2017; 274: 2945-51. [CrossRef]

2. Lee CH, Chang WH, Ko JY, Yeh TH, Hsu WC, Kang KT. Revision adenoidectomy in children: a population-based cohort 
study in Taiwan. Eur Arch Otorhinolaryngol 2017; 274: 3627-35. [CrossRef]

3. Mikals SJ, Brigger MT. Adenoidectomy as an adjuvant to primary timpanostomy tube placement: a systematic review and meta-analysis. JAMA Otolaryngol Head Neck Surg 2014; 140: 95101. [CrossRef]

4. Marchisio P, Nazzari E, Torretta S, Esposito S, Principi N. Medical prevention of recurrent acute otitis media: an updated overview. Expert Rev Anti Infect Ther 2014; 12: 611-20. [CrossRef]

5. Santagati M, Scillato M, Muscaridola N, Metoldo V, La Mantia I, Stefani S. Colonization, safety, and tolerability study of the Streptococcus salivarius $24 \mathrm{SMBc}$ nasal spray for its application in upper respiratory tract infections. Eur J Microbiol Infect Dis 2015; 34: 2075-80. [CrossRef]

6. La Mantia I, Varricchio A, Ciprandi G. Bacteriotherapy with Streptococcus salivarius 24SMB and Streptococcus oralis 89a na- sal spray for preventing recurrent acute otitis media in children: a real-life clinical experience. Int J Gen Med 2017; 10: 171-5. [CrossRef]

7. Malannino N, Alberti M, Giardina V, et al. Valutazione dell'ipertrofia adenoidea e imaging endoscopico. Consensus on Respiratory Diseases 1998; 5: 217-21.

8. Bernstein JM, Faden HF, Dryja DM, Wactawski-wende J. Micro-ecology of the nasopharyngeal bacterial flora in otitis-prone and non-otitis-prone children. Arch Otolaryngol 1993; 113: 8892. [CrossRef]

9. Cohen R, Martin E, de La Rocque F, Thollot F, Pecquet S, Werner $\mathrm{A}$, et al. Probiotics and prebiotics in preventing episodes of acute otitis media in high-risk children: a randomized, double-blid, placebo-controlled study. Ped Infect Dis J 2013; 32: 810-4. [CrossRef] 